\title{
Endoscopic treatment of early leaks and strictures after laparoscopic one anastomosis gastric bypass
}

\author{
Fadi Younis ${ }^{1}$, Mati Shnell ${ }^{1}$, Nathan Gluck ${ }^{1}$, Subhi Abu-Abeid ${ }^{2}$, Shai Eldar ${ }^{2}$ and Sigal Fishman ${ }^{{ }^{*}}$ (D
}

\begin{abstract}
Background: Laparoscopic one anastomosis gastric bypass has become a prominent bariatric procedure. Yet, early and late complications, primarily leaks and strictures, are not uncommon. This study summarizes our experience with endoscopic treatment of laparoscopic one anastomosis gastric bypass complications.

Methods: This is a retrospective study of consecutive patients referred to our hospital from 2015 to 2017 with post laparoscopic one anastomosis gastric bypass complications. Therapy was tailored to each case, including fully covered self-expandable metal stents, fibrin glue, septotomy, internal drainage with pigtail stents, through-thescope and pneumatic dilation. Success was defined as resuming oral nutrition without enteral or parenteral support or further surgical intervention.

Results: Nine patients presented with acute or early leaks: 5 (56\%) had staple-line leaks, 3 (33\%) had anastomotic leaks and $1(11 \%)$ had both. All were treated with stents. Adjunctive endoscopic drainage was applied in 4 patients (44\%). Overall 5 patients (56\%) with acute/ early leaks recovered completely, including all 3 patients with anastomotic leak and the patient with both leaks but only 1/5 with staple line leak (20\%). Complication rate in the leak group reached $22 \%$. Eight patients presented with strictures, 7 at the anastomosis and one due to remnant stomach misalignment. All anastomotic strictures were dilated successfully. However, the patient with the pouch stricture required conversion to Roux-en-Y gastric bypass after 3 failed attempts of dilation.

Conclusion: Endoscopic treatments of laparoscopic one anastomosis gastric bypass complications are relatively effective and safe. Anastomosis-related complications are more amenable to endoscopic treatment compared to staple line leaks.
\end{abstract}

Keywords: Laparoscopic one anastomosis gastric bypass, Postoperative complications, Bariatric endoscopy, Stents, Dilation

\section{Background}

Morbid obesity has become a major global health threat that leads to severe morbidity including diabetes, hypertension, obstructive sleep apnea, degenerative joint disease and cardiovascular diseases. To date, bariatric surgery is the most effective intervention for weight reduction and remission of associated comorbidities [1]. Laparoscopic one anastomosis gastric bypass (LOAGB), introduced in 1997 [2], is gaining popularity and has

\footnotetext{
* Correspondence: sigalf@tlvmc.gov.il

1Obesity Service, Department of Gastroenterology and Liver Disease, Tel Aviv Sourasky Medical Center, affiliated with Sackler School of Medicine, Tel Aviv University, 6 Weizmann St, Tel Aviv, Israel

Full list of author information is available at the end of the article
}

become the fourth most performed surgery in Europe and the Asia/Pacific area [1,3]. Results with LOAGB in terms of weight loss and resolution of comorbidities have been promising [4-6]. Still, early and late complications occur at an estimated rate of 3.1 and $10 \%$ respectively [7]. Potential adverse events include postoperative or chronic leaks and strictures. Endoscopic management of postoperative leaks is challenging and constantly evolving with no clear guidelines. The aim of endoscopic treatment is to divert gut secretion away from the leak site to allow fistula healing and resuming oral nutrition as early as possible. These goals may be achieved by deploying fully covered self-expanding metal stents (FC-

(c) The Author(s). 2020 Open Access This article is distributed under the terms of the Creative Commons Attribution 4.0 International License (http://creativecommons.org/licenses/by/4.0/), which permits unrestricted use, distribution, and 
SEMS) [8-13]. Other strategies including over the scope clips, fibrin glue, endoscopic suturing and intragastric drainage (IGD) with double pigtail stent have been all described with variable success rate [9, 14-17]. In cases of chronic leak with perigastric collection formation, the preferred and effective endoscopic approach is to enable adequate drainage of the perigastric collection into the stomach by dissecting the septum separating the two cavities (septotomy) [18] or by inserting double pigtail stent. Post-surgical strictures are treated with endoscopic dilation. While anastomotic strictures are amenable to through the scope (TTS) dilation with high success rates $[19,20]$, post laparoscopic sleeve gastrectomy (LSG) strictures due sleeve misalignment are more difficult to treat. In these cases pneumatic dilation is preferred [21]. The aim of this study was to summarize our experience in treating post LOAGB complications amenable to endoscopic treatment, namely leaks and strictures.

\section{Methods}

This was a retrospective study of consecutive patients referred to our department with post LOAGB leaks or strictures between August 2015 and October 2017. The diagnosis was based upon symptoms, imaging and endoscopic studies. Patients were managed by a multidisciplinary team that included bariatric surgeons, gastroenterologists from the bariatric endoscopy service, invasive radiologists and nutritionists.

\section{Postoperative leaks}

In all cases fully covered stents (Esophageal Mega stent, length $23 \mathrm{~mm}$, diameter $24 \mathrm{~mm}$, Teawoong, Seoul, Korea) were introduced over a stiff guidewire (38-in. Amplatz Super Stiff, Boston Scientific, Marlborough, Mass, USA) with fluoroscopic guidance, under conscious sedation. The proximal third of the stent was located above the gastroesophageal junction and the distal end was placed in the efferent limb. Fluoroscopy was performed 1 day after the procedure to confirm correct positioning of the stent and resolution of the leak after which patients gradually resumed a soft oral diet. Our target duration of treatment was 2-6 weeks and was individualized by drainage output when a drain was placed, the nature of the fluid and patient tolerability. In cases where the leak evolved to a late or chronic form (>6 or 12 weeks, respectively), internal drainage was achieved by septotomy (see Introduction) or pigtail insertion into the collection cavity. Septotomy was performed by incising the septum with argon plasma coagulation (Erbe Vio 200 D; forced coagulation, $70 \mathrm{~W}$, $2 \mathrm{~L} / \mathrm{min}$ ) along the staple-line towards the base of the perigastric cavity, which was endoscopically identified. Importantly, the incision of the septum never exceeded the base of the cavity. As a precaution, the incision was performed gradually, with a maximal incision depth of 5-10 mm during each session until the cavity was entered. Patients resumed an oral liquid diet once adequate intragastric drainage had been achieved. Double pigtail stent with a diameter of $7 \mathrm{Fr}$ and length of $7 \mathrm{~cm}$ (Cook Medical) were inserted under fluoroscopy into persistent residual sinuses. All procedures were performed using $\mathrm{CO} 2$ insufflation (Fig. 1).

\section{Postoperative strictures}

All patients were treated with balloon dilation. Anastomotic strictures were treated with TTS balloon dilation $\left(\mathrm{CRE}^{\mathrm{T \omega}}\right.$ Balloon Dilation Catheters; Boston Scientific, Natick, MA, USA). The balloon was gradually inflated up to maximal diameter of $20 \mathrm{~mm}$. The procedure was repeated as needed. Remnant stomach misalignment resulting in mid gastric kink was treated with pneumatic balloon dilation (Rigiflex II balloon; Boston Scientific, Natick, MA, USA). The procedure was performed under direct vision and fluoroscopy with continuous inflation up to a maximal diameter of $30 \mathrm{~mm}$ and pressure of 20 PSI in each session. The balloon was held maximally inflated within the stricture for $1 \mathrm{~min}$. When two consecutive procedures did not alleviate the symptoms the patient was referred to surgery.

Success was defined as resuming oral nutrition without enteral or parenteral support or further surgical intervention.

\section{Statistical analysis}

Continuous variables were tested for normality. Normally distributed parameters were described as mean \pm standard deviation, where skewed parameters were describes as median (interquartile range, IQR), and categorical as N (\%) using SPSS (IBM SPSS Statistics for Windows, Version 21.0. 2012, Armonk, NY: IBM Corp.)

\section{Results}

Seventeen patients were referred to our clinic, 9 with postoperative leaks and 8 with postoperative strictures.

\section{Postoperative leak group}

Nine patients were included in this group, all were presented less than 4 weeks after surgery, 5/9 male, with a mean age of $41 \pm 11$ years (range 23-57) and pre-operative mean body mass index (BMI) of $44 \pm 8$ $(\mathrm{kg} / \mathrm{m} 2)$. Interestingly, six patients $(67 \%)$ had revisions from previous bariatric surgery including laparoscopic adjustable gastric banding (LAGB), silastic ring vertical gastroplasty (SRVG) and laparoscopic sleeve gastrectomy, 3 of which had two previous operations (Table 1). Neither of the patients developed frank peritonitis or needed another surgical procedure. All 

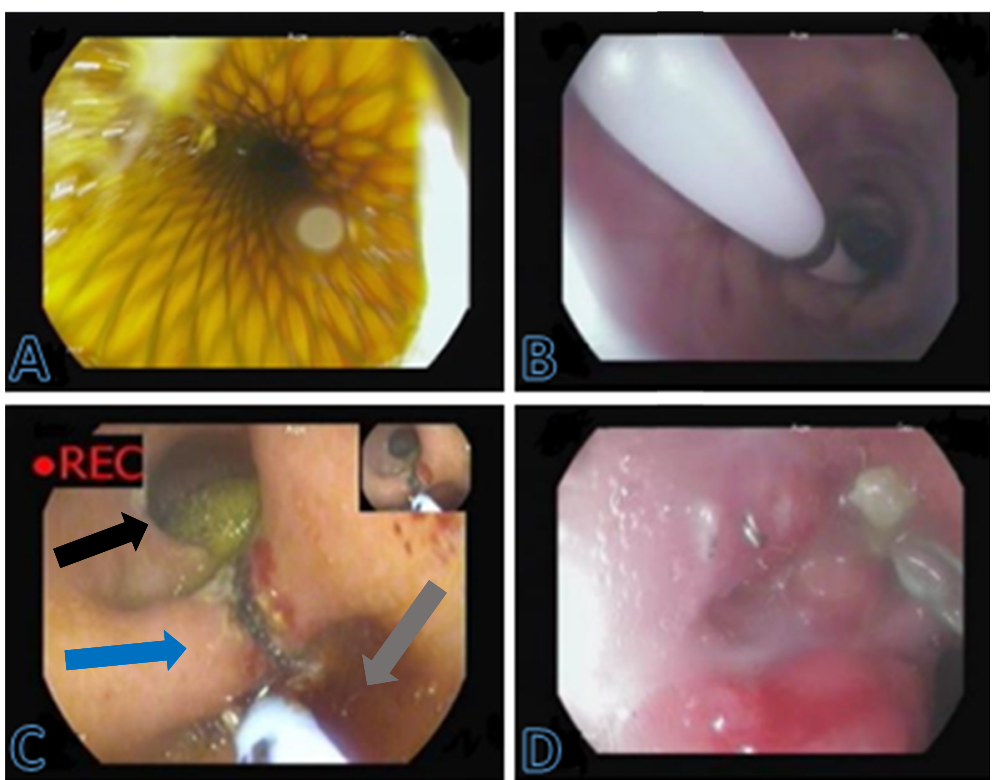

Fig. 1 Treatment of a staple-line leak. a. Treatment at the acute phase with stent deployment. $\mathbf{b}$. Treatment at the late phase with pneumatic dilation of the remnant stomach. $\mathbf{c}$. Septotomy performed to unify the perigastric collection and the remnant stomach cavity, views showing the perigastric space (black arrow), remnant stomach lumen (gray arrow) and septum (blue arrow). d. A healed fistula

cases were diagnosed by computed tomography. Endoscopic management applied in each patient and outcomes are depicted in Table 2. Eight patients (89\%) had an early leak (1-6 week) and one had an (11\%) acute leak ( $<1$ week). Five patients $(56 \%)$ presented with a proximal staple-line leak (at the angle of His), 3 (33\%) with an anastomotic leak and 1 (11\%) with leaks at both sites. Median time between surgery and first endoscopy was 12 days (IQR 10-19) and the median number of therapeutic endoscopic sessions was 3 (IQR 2-6). All patients were treated

Table 1 Patient demographics and surgical details of postoperative leak group

\begin{tabular}{lll}
\hline Patient number & BMI $(\mathrm{Kg} / \mathrm{m} 2)$ & Previous operation \\
\hline 1 & 37 & None \\
2 & NA & LAGB + LSG \\
3 & 38 & LAGB + LSG \\
4 & 46 & SRVG \\
5 & 38 & None \\
6 & 40 & None \\
7 & 60 & LAGB $\times 2$ \\
8 & NA & LAGB \\
9 & NA & LSG \\
\hline
\end{tabular}

BMI Body mass index, LAGB Laparoscopic adjustable gastric banding, LSG Laparoscopic sleeve gastrectomy, NA Not available, SRVG Silastic ring vertical gastroplasty with fully covered stents for a median period of 26 days (IQR 11-30). Additional endoscopic treatment was required in 4 patients (45\%). Three of them needed ancillary dilation. The first needed a single TTS balloon dilation $(15 \mathrm{~mm})$ of an anastomotic stricture. The second needed a single pneumatic balloon $(30 \mathrm{~mm})$ dilation of a mid-pouch stricture. The third developed a late stricture at the esophageal gastric junction, treated with gradual TTS dilation up to 20 $\mathrm{mm}$. Two patients with staple line leak evolved to late fistula and needed additional drainage procedures including septotomy, double pigtail stent insertion and tissue glue (Table 2).

Overall, 5 of 9 patients (56\%) were successfully treated as defined by weaning from total parenteral nutrition, resuming oral diet, removal of intraabdominal draining tubes, and avoidance of further surgical intervention with a follow up of approximately 6 months (Table 2). All 3 patients with anastomotic leak had a favorable outcome. However only 1 of 5 patients with staple line leak had a favorable outcome. Of note, the patient with both anastomoticand staple line-leaks recovered.

Two patients were referred to Roux-en-Y- gastric bypass (RYGB) conversion. One patient needed urgent laparotomy after 2 weeks of treatment due to stent migration and ileum perforation. Interestingly, this patient did not require further treatment for his staple-line leak. The forth patient died due to 
Table 2 Endoscopic leak management and outcomes

\begin{tabular}{|c|c|c|c|c|c|c|c|c|}
\hline $\begin{array}{l}\text { Patient } \\
\text { number }\end{array}$ & Leak site & $\begin{array}{l}\text { Days from surgery } \\
\text { to leak diagnosis } \\
\text { (type of leak) }\end{array}$ & $\begin{array}{l}\text { Days from } \\
\text { surgery to first } \\
\text { endoscopy }\end{array}$ & $\begin{array}{l}\text { Number of } \\
\text { therapeutic } \\
\text { endoscopies }\end{array}$ & $\begin{array}{l}\text { Stent duration } \\
\text { (days) }\end{array}$ & $\begin{array}{l}\text { Number of stent } \\
\text { replacements/ } \\
\text { repositions }\end{array}$ & $\begin{array}{l}\text { Additional } \\
\text { treatment }\end{array}$ & Result \\
\hline 1 & $\begin{array}{l}\text { Anastomosis } \\
\text { Staple line } e^{a}\end{array}$ & 9 (early) & 10 & 6 & 36 & - & GEJ. Dilation & Success \\
\hline 2 & Staple line ${ }^{a}$ & 14 (early) & 21 & 7 & 30 & 1 & $\begin{array}{l}\text { Anastomosis } \\
\text { Dilation } \\
\text { Septotomy }\end{array}$ & Success \\
\hline 3 & Staple line $e^{a}$ & 7 (early) & 10 & 12 & 25 & 4 & $\begin{array}{l}\text { Septotomy } \\
\text { Pigtail } \\
\text { Tissue glue }\end{array}$ & Failure \\
\hline 4 & Anastomosis & 9 (early) & 10 & 3 & 8 & - & No & Success \\
\hline 5 & Anastomosis & 26 (early) & 6 & 2 & 19 & - & No & Success \\
\hline 6 & Staple line ${ }^{a}$ & 14 (early) & 17 & 2 & 1 & - & No & Failure \\
\hline 7 & Staple line ${ }^{a}$ & 5 (acute) & 29 & 3 & 30 & 1 & $\begin{array}{l}\text { Mid Pouch. } \\
\text { Dilation }\end{array}$ & Failure \\
\hline 8 & Anastomosis & 10 (early) & 12 & 2 & 26 & - & No & Success \\
\hline 9 & Staple line ${ }^{a}$ & 11 (early) & 16 & 1 & 14 & - & No & Failure \\
\hline
\end{tabular}

GEJ Gastroesophageal junction

${ }^{a}$ At the angle of His

respiratory failure secondary to severe pneumonia probably not related to the endoscopic procedure. Of note, 3 of 4 failed patients (75\%) had previous bariatric surgery.

\section{Postoperative stricture group}

Eight patients were diagnosed with stricture based upon symptoms of vomiting and excessive weight loss. All of them were female with a mean age of $49 \pm 14$ years (range 24-65) and preoperative mean BMI of $39 \pm 9(\mathrm{~kg} / \mathrm{m} 2)$. Four patients $(50 \%)$ had previous bariatric surgery including LAGB and LSG (Table 3). Stricture site and mode of treatment are depicted in Table 4. Seven patients (88\%) presented with anastomotic stricture and one patient (12.5\%)

Table 3 Patient demographics and surgical details of postoperative stricture group

\begin{tabular}{lll}
\hline Patient number & BMl $(\mathrm{kg} / \mathrm{m} 2)$ & Previous operation \\
\hline 1 & 37 & No \\
2 & 46 & No \\
3 & NA & LSG \\
4 & 39 & No \\
5 & NA & LAGB \\
6 & 48 & LSG \\
7 & 23.3 & LSG \\
8 & 40 & No \\
\hline
\end{tabular}

BMI Body mass index, CT Computed tomography, LAGB Laparoscopic adjustable gastric banding, LSG Laparoscopic sleeve gastrectomy, NA Not available with a mid-pouch kink. The median time between surgery and the first endoscopic dilation was 63 days (IQR 37-140), and the median number of therapeutic endoscopic dilation was 3 (2-4). Anastomotic strictures were TTS-dilated with a maximal balloon diameter of $20 \mathrm{~mm}$ and the pouch stricture was pneumatically dilated with a balloon diameter of $30 \mathrm{~mm}$. Overall success rate was $88 \%$. All 7 patients with anastomotic stricture reported significant clinical improvement with a follow up of 6 months after the last procedure (Table 4). The patient with the pouch kink was defined as a treatment failure due to persistent vomiting and weight loss after 3 attempts of pneumatic dilation and finally underwent conversion to formal RYGB surgery.

\section{Discussion}

Herein we demonstrate that endoscopic treatment of post-LOAGB leaks and strictures is can be effective and is safe. To our knowledge this is the largest series described to date. In 10 of 17 patients a previous bariatric procedure had been performed (59\%), which is a known risk factor for post-surgery complications [22, 23]. Interestingly, LOAGB complications may be divided into anastomosis-related stricture and leaks which resemble those of RYGB [24-26], and staple line leaks and remnant stomach axis deviation (kink) which are similar to those of LSG [27-29]. Our data show a $100 \%(7 / 7)$ success rate in TTS dilation of anastomotic strictures without any complications at a mean follow up of 6 months, similar to the 93-100\% success rate for post RYGB anastomotic 
Table 4 Endoscopic dilation of strictures and outcomes

\begin{tabular}{lllllll}
\hline Patient number & Stricture site & $\begin{array}{l}\text { Days from surgery } \\
\text { to first dilation }\end{array}$ & $\begin{array}{l}\text { Number of } \\
\text { therapeutic dilations }\end{array}$ & Type of dilation & Maximal size of dilation & Result \\
\hline 1 & Anastomosis & 147 & 2 & TTS & $20 \mathrm{~mm}$ & $18 \mathrm{~mm}$ \\
2 & Anastomosis & 50 & 5 & TTS & $20 \mathrm{~mm}$ & Success \\
3 & Anastomosis & 30 & 1 & TTS & Success \\
4 & Anastomosis & 33 & 3 & TTS & $15 \mathrm{~mm}$ & Success \\
5 & Anastomosis & 160 & 4 & TTS & $20 \mathrm{~mm}$ & Success \\
6 & Anastomosis & 117 & 3 & TTS & $30 \mathrm{~mm}$ & Success \\
7 & Pouch & 60 & 3 & P & TUccess \\
8 & Anastomosis & 66 & 3 & TTS & Failure \\
\hline
\end{tabular}

$P$ Pneumatic, TTS Through-the-scope

stricture dilation [30]. Anastomotic leaks controlled with stent insertion also exhibited a favorable outcome with $100 \%$ success $(3 / 3)$. In contrast, treatment of staple line leaks exhibited a less favorable outcome with a success rate of only $20 \%(1 / 5)$, compared to 65-95\% in acute and early leaks after LSG [30]. Of note, two patients evolved to a late type of leak and received ancillary drainage with septotomy and double pigtail stent. Although we achieved excellent control of late and chronic leaks after LSG with this approach [18], currently it succeeded in only one patient. Another patient had remnant stomach misalignment (kink) with failure to dilate it pneumatically. Interestingly there was high rate of treatment failure of staple line-related complications in patients with previous bariatric procedures $(60 \%)$ which supports the possibility of causality.

A recent study described 46 leaks in one anastomosis gastric bypass out of 2780 operated patients. This series highlights the effectiveness of the endoscopic treatment, as $20 \%$ of the primary management was done successfully by this mean [31].

The safety profile of endoscopic treatment could be further improved. Overall, we had two major complications. One case of stent migration resulted in small bowel perforation which necessitated urgent laparotomy. One death occured, however it was not related to the endoscopic procedure.

Our study has several limitations. These include a relatively small group of patients, performance at a single tertiary referral centre, and no control group in the study design. Multicentric trials, with greater sample sizes are necessary.

\section{Conclusion}

Endoscopic treatment of LOAGB complications can be effective and relatively safe. Anastomosis-related complications are more amenable to endoscopic treatment compared to staple line related complications.

\section{Abbreviations}

BMI: Body mass index; FC-SEMS: Fully covered self-expanding metal stents; IGD: Intragastric drainage; LOAGB: Laparoscopic one anastomosis gastric bypass; LSG: Laparoscopic sleeve gastrectomy; OTSC: Over the scope clips; RYGB: Roux-en-Y-gastric bypass; TTS: Through the scope

\section{Acknowledgements}

Not applicable.

\section{Authors' contributions}

FY, NG and SF collected and performed the data analysis and contributed to the writing of the manuscript. MS and FY performed the literature search and statistical analyses. SAA, SF and SE, interpretation of data, contributed to the discussion and final approval of the manuscript. All authors have read and approved the final version of the manuscript.

\section{Funding}

There are no resources of funding to be reported or declared.

Availability of data and materials

From the corresponding author on reasonable request.

\section{Ethics approval and consent to participate}

The study was approved by the local ethic review board of Tel Aviv Sourasky Medical Center. Patients informed consent was not required due to the retrospective nature of the study.

\section{Consent for publication}

Not applicable.

\section{Competing interests}

The authors declare that they have no competing interests.

\section{Author details}

${ }^{1}$ Obesity Service, Department of Gastroenterology and Liver Disease, Tel Aviv Sourasky Medical Center, affiliated with Sackler School of Medicine, Tel Aviv University, 6 Weizmann St, Tel Aviv, Israel. 'Bariatric Unit, Department of Surgery, Tel Aviv Sourasky Medical Center, Tel Aviv, Israel.

Received: 29 August 2019 Accepted: 22 January 2020

Published online: 21 February 2020

\section{References}

1. Angrisani L, Santonicola A, lovino P, Formisano G, Buchwald H, Scopinaro N. Bariatric surgery worldwide 2013. Obes Surg. 2015. https://doi.org/10.1007/ s1 1695-015-1657-z.

2. Rutledge R. The mini-gastric bypass: experience with the first 1,274 cases; 2001

3. Angrisani L, Santonicola A, lovino P, Formisano G, Buchwald H, Scopinaro N. Reply to Letter to the Editor: Bariatric Surgery Worldwide 2013 Reveals a Rise in Mini-Gastric Bypass. Obes Surg. 2015;25(11):2166-8.

4. Chevallier JM, Arman GA, Guenzi M, Rau C, Bruzzi M, Beaupel N, et al. One thousand single anastomosis (omega loop) gastric bypasses to treat morbid 
obesity in a 7-year period: outcomes show few complications and good efficacy. Obes Surg. 2015. https://doi.org/10.1007/s11695-014-1552-z.

5. Lee WJ, Ser KH, Lee YC, Tsou JJ, Chen SC, Chen JC. Laparoscopic roux-en-Y Vs. Mini-gastric bypass for the treatment of morbid obesity: A 10-year experience. Obes Surg. 2012. https://doi.org/10.1007/s11695-012-0726-9.

6. Musella M, Susa A, Greco F, De Luca M, Manno E, Di Stefano C, et al. The laparoscopic mini-gastric bypass: the Italian experience: outcomes from 974 consecutive cases in a multicenter review. Surg Endosc Other Interv Tech. 2014. https://doi.org/10.1007/s00464-013-3141-y.

7. Musella M, Susa A, Manno E, De Luca M, Greco F, Raffaelli M, et al. Complications following the mini/one anastomosis gastric bypass (MGB/ OAGB): a multi-institutional survey on 2678 patients with a mid-term (5 years) follow-up. Obes Surg. 2017. https://doi.org/10.1007/s11695-017-2726-2.

8. Abou Rached A, Basile M, El Masri H. Gastric leaks post sleeve gastrectomy: Review of its prevention and management. World I Gastroenterol. 2014; 20(38):13904-10

9. Casella G, Soricelli E, Rizzello M, Trentino P, Fiocca F, Fantini A, et al. Nonsurgical treatment of staple line leaks after laparoscopic sleeve Gastrectomy. Obes Surg. 2009. https://doi.org/10.1007/s11695-009-9840-8.

10. Eisendrath P, Cremer M, Himpens J, Cadière GB, Le Moine $\mathrm{O}$, Devière J. Endotherapy including temporary stenting of fistulas of the upper gastrointestinal tract after laparoscopic bariatric surgery. Endoscopy. 2007. https://doi.org/10.1055/s-2007-966533.

11. Eubanks S, Edwards CA, Fearing NM, Ramaswamy A, de la Torre RA, Thaler $\mathrm{K}$, et al. Use of endoscopic stents to treat anastomotic complications after bariatric surgery. J Am Coll Surg. 2008. https://doi.org/10.1016/j.jamcollsurg. 2008.02.016.

12. Nguyen NT, Nguyen XMT, Dholakia C. The use of endoscopic stent in management of leaks after sleeve gastrectomy. Obes Surg. 2010. https://doi. org/10.1007/s11695-010-0186-z.

13. Tan JT, Kariyawasam S, Wijeratne T, Chandraratna HS. Diagnosis and management of gastric leaks after laparoscopic sleeve gastrectomy for morbid obesity. Obes Surg. 2010. https://doi.org/10.1007/s11695-009-0020-7.

14. Corona M, Zini C, Allegritti M, Boatta E, Lucatelli P, Cannavale A, et al. Minimally invasive treatment of gastric leak after sleeve gastrectomy. La Radiologia medica. 2013. https://doi.org/10.1007/s11547-013-0938-7.

15. Lee YC, Na HG, Suh JH, Park IS, Chung KY, Kim NK. Three cases of fistulae arising from gastrointestinal tract treated with endoscopic injection of histoacry| ${ }^{\oplus}$. Endoscopy. 2001. https://doi.org/10.1055/s-2001-11670.

16. Overcash WT. Natural orifice surgery (NOS) using Stomaphy $X^{T M}$ for repair of gastric leaks after bariatric revisions. Obes Surg. 2008. https://doi.org/10. 1007/s11695-008-9452-8.

17. Papavramidis TS, Kotzampassi K, Kotidis E, Eleftheriadis EE, Papavramidis ST. Endoscopic fibrin sealing of gastrocutaneous fistulas after sleeve gastrectomy and biliopancreatic diversion with duodenal switch. J Gastroenterol Hepatol (Australia). 2008. https:/doi.org/10.1111/j.1440-1746.2008.05545.x.

18. Shnell M, Gluck N, Abu-Abeid S, Santo E, Fishman S. Use of endoscopic septotomy for the treatment of late staple-line leaks after laparoscopic sleeve gastrectomy. Endoscopy. 2017. https://doi.org/10.1055/s-0042-117109.

19. Da Costa M, Mata A, Espinós J, Vila V, Roca JM, Turró J, et al. Endoscopic dilation of gastrojejunal anastomotic strictures after laparoscopic gastric bypass. Predictors of initial failure. Obes Surg. 2011. https://doi.org/10.1007/ s11695-010-0154-7.

20. Ukleja A, Afonso BB, Pimentel R, Szomstein S, Rosenthal R. Outcome of endoscopic balloon dilation of strictures after laparoscopic gastric bypass. Surg Endosc. 2008. https://doi.org/10.1007/s00464-008-9788-0.

21. Shnell M, Fishman S, Eldar S, Goitein D, Santo E. Balloon dilatation for symptomatic gastric sleeve stricture. Gastrointest Endosc. 2014. https://doi. org/10.1016/j.gie.2013.09.026.

22. Coblijn UK, Karres J, de Raaff CAL, de Castro SMM, Lagarde SM, van Tets WF, et al. Predicting postoperative complications after bariatric surgery: the bariatric surgery index for complications, BASIC. Surg Endosc Other Interv Tech. 2017. https://doi.org/10.1007/s00464-017-5494-0.

23. Zhang L, Tan WH, Chang R, Eagon JC. Perioperative risk and complications of revisional bariatric surgery compared to primary roux-en-Y gastric bypass. Surg Endosc. 2015. https://doi.org/10.1007/s00464-014-3848-4.

24. Ballesta C, Berindoague R, Cabrera M, Palau M, Gonzales M. Management of anastomotic leaks after laparoscopic roux-en-Y gastric bypass. Obes Surg. 2008. https://doi.org/10.1007/s11695-007-9297-6.

25. Fernandez AZ, DeMaria EJ, Tichansky DS, Kellum JM, Wolfe LG, Meador J, et al. Experience with over 3,000 open and laparoscopic bariatric procedures: multivariate analysis of factors related to leak and resultant mortality. Surg Endosc Other Interv Tech. 2004. https://doi.org/10.1007/ s00464-003-8926-y.

26. Jones KB, Afram JD, Benotti PN, Capella RF, Cooper CG, Flanagan L, et al. Open versus laparoscopic roux-en-Y gastric bypass: a comparative study of over 25,000 open cases and the major laparoscopic bariatric reported series. Obes Surg. 2006. https://doi.org/10.1381/096089206777346628.

27. Aurora AR, Khaitan L, Saber AA. Sleeve gastrectomy and the risk of leak: a systematic analysis of 4,888 patients. Surg Endosc Other Interv Tech. 2012. https://doi.org/10.1007/s00464-011-2085-3.

28. Sarkhosh K, Birch DW, Sharma A, Karmali S. Complications associated with laparoscopic sleeve gastrectomy for morbid obesity: A surgeon's guide. Can J Surg. 2013;56(5):347-52.

29. Southwell T, Lim TH, Ogra R. Endoscopic therapy for treatment of staple line leaks post-laparoscopic sleeve Gastrectomy (LSG): experience from a large bariatric surgery Centre in new Zealand. Obes Surg. 2016. https://doi.org/10. 1007/s11695-015-1931-0.

30. Joo MK. Endoscopic approach for major complications of bariatric surgery. Clin Endosc. 2017;50(1):31-41.

31. Liagre A, Queralto M, Juglard G, Anduze Y, lannelli A, Martini F. Multidisciplinary Management of Leaks after one-Anastomosis Gastric Bypass in a single-center series of 2780 consecutive patients. Obes Surg. 2019. https://doi.org/10.1007/s11695-019-03754-2.

\section{Publisher's Note}

Springer Nature remains neutral with regard to jurisdictional claims in published maps and institutional affiliations.
Ready to submit your research? Choose BMC and benefit from:

- fast, convenient online submission

- thorough peer review by experienced researchers in your field

- rapid publication on acceptance

- support for research data, including large and complex data types

- gold Open Access which fosters wider collaboration and increased citations

- maximum visibility for your research: over $100 \mathrm{M}$ website views per year

At BMC, research is always in progress.

Learn more biomedcentral.com/submissions 